\title{
O tempo como dispositivo
}

\section{Franz Manata ${ }^{1}$}

Resumo: Em um "diálogo" com Clark, Deleuze, Duchamp, Espinosa, Long, Meireles, Vaz e Viveiros de Castro, quero demonstrar que existe um léxico operando na arte atual, transformando a noção de construção herdada da tradição brasileira, com conceitos e apreensões particulares, que altera o papel social do artista e o próprio objeto da arte ao tornar o tempo dispositivo.

Palavras-chave: arte, tempo, filosofia, dispositivo

\section{Time as a device}

Abstract: In "dialogue" with Clark, Deleuze, Duchamp, Espinosa, Long, Meireles, Vaz and Viveiros de Castro, I want to demonstrate that there is a lexicon operating in current art, transforming the notion of construction inherited from the Brazilian tradition, with concepts and particular apprehensions, which alters the social role of the artist and the very object of art by making time a device.

Keywords: art, time, philosophy, device

1 Artista, pesquisador e professor. Mestre em Linguagens Visuais pela EBA-UFRJ com formação em Economia e especialização em Sociologia e Administração Financeira na PUC-MG. Nos últimos anos vem realizando curadorias, publicando textos, participando de debates e comissões de seleção. Leciona, desde 2004, na EAV Parque Lage, RJ e integra, desde 1998, o duo Manata Laudares, representado pela Sé Galeria, São Paulo. O duo vem participando de exposições individuais e coletivas, no Brasil e exterior. Parque Lage (EAV). E-mail: franzmanata@gmail.com. ORCID: https://orcid.org/0000-0002-4851-1550. Lattes iD: http://lattes.cnpq.br/3711702215701139. Rio de Janeiro, Brasil 
"A lógica de um pensamento não é um sistema racional em equilíbrio".

Gilles Deleuze

\section{Apresentação}

Só nos resta o tempo. Não o da mensura ou espera, mas o da ação, no qual o trabalho do artista torna-se um dispositivo de tempo totalmente desprovido de valor de troca - na realidade, a forma é suprimida como problema e não como algo a ser administrado no percurso. A obra torna-se uma apreensão de tempo, que se dá na duração dos deslocamentos do artista. Agora, o tempo torna-se o dispositivo central.

Há muito que não temos pensado ou produzido objetos e espaços como um problema central do trabalho. No nosso entender, as questões do espaço e da representação, que sempre foram específicas da arte, foram apropriadas e deslocadas para as áreas congêneres da criação e só nos sobrou o tempo como objeto.

No momento em que nos encontramos afogados na superestrutura mercantil e de modelagem das subjetividades por dispositivos tecnológicos, o que nos interessa ressaltar é o dispositivo como instrumento de mediação objetiva no mundo, como condição imanente ao indivíduo, aquele que permanece no âmbito da experiência possível, agindo na captação da realidade através dos sentidos, fazendo com que a realidade seja vivenciada de modo pessoal e existente, para além do objeto, e na positividade. Portanto, o que quero ressaltar aqui é o tempo como dispositivo, um tipo de artifício que usamos em nosso trabalho e que se manifesta como ação (escolha ética) que se dá de forma objetiva no mundo (espaço) e no corpo (tempo).

Para esclarecer essas questões e apresentar melhor os lastros conceituais e sua formação, é necessário estabelecer um "diálogo" com alguns artistas e pensadores que "emprestaram" densidade e formaram meu pensamento. A lista é longa, e entre os que admiro escolhi aqueles cuja obra se mostra importante para nos ajudar a compreender algumas ideias contidas em nossa prática artística, que aqui quero apresentar: Marcel Duchamp, que 
ao expor a noção de circuito artístico introduz a problemática do tempo vivido; Richard Long, que me fez pensar na experiência da duração pela primeira vez; Cildo Meireles, na ação objetiva no mundo; Lygia Clark, na supressão do objeto; e, Guilherme Vaz, o único a realizar uma obra inteiramente no tempo. Não menos importante para o "diálogo" é a contribuição de Espinosa acerca da substância; de Deleuze com o devir inumano; e o perspectivismo multinaturalista de Viveiros de Castro.

O que pretendo demonstrar é que já existe outro léxico operando na arte atual, que transforma a noção de construção herdada da tradição construtiva brasileira, alterando por completo o objeto da arte, o papel social do autor, a maneira de transmitir conhecimento e seu modo de circulação.

A arte contemporânea - esse campo do conhecimento que se manifesta segundo condições específicas - usa a palavra dispositivo em abundância, até com certa banalidade, para garantir sua especificidade. Artistas, curadores, críticos e historiadores fazem uso em larga escala para determinar uma forma, uma disposição, uma prescrição ou ordem. O fato é que "dispositivo" assume vários papéis na subjetivação do sujeito transcendente, que geralmente é fundado em uma imagem espacial, em que "transcender" significa ir para um "outro lugar", cruzar um certo limite cognitivo, tornando-nos capaz de "mediar" a experiência sensível.

Não há uma grande mostra realizada neste século que não faça uso do termo dispositivo como artifício técnico na sua elaboração e na sustentação conceitual de obras e artistas. Para citar apenas um exemplo, a $32^{\text {a }}$ Bienal de São Paulo - "Incerteza viva" - , em 2016, como toda mostra de grande porte, usou diferentes dispositivos de exposição e difusão para mediar de forma mais específica o contato do público para a produção de conhecimento num evento coletivo de tal monta. No livro da mostra há a menção da palavra dispositivo em vinte páginas, com os mais diversos usos: como na construção de "dispositivos que organizam, catalogam e medem, como mapas, bandeiras, relógios e livros didáticos", 2 usados por Lais Myrrha para construir esculturas que são "mecanismos através dos quais formas de poder e dominação se exercem"3 (Fábio Zuker); ou nos agenciamentos de Jorge Menna Barreto que podem se tornar "um dispositivo que procura

2 32a Bienal de São Paulo, Incerteza viva, 2016, p. 234.

3 Ibidem. 
ativar no público a consciência da especificidade do lugar"4 (Cecília Bedê); ou nos "dispositivos móveis" do coletivo OPAVIVARA!, que são objetos apropriados do mundo ordinário e transformados para "interação pública"5 (Marília Loureiro); ou ainda, no trabalho do duo Nomeda \& Gediminas Urbonas que usam "dispositivos para mobilização social comunitária que promovem a ação colaborativa" para "colisões e rupturas no espaço social onde atuam" e, assim, permitir a "consciência do espaço"6 (Diego Matos). Esses são apenas alguns exemplos de como críticos adjetivam os trabalhos e artistas da mostra, tornando o dispositivo uma ferramenta de catalogação e organização; ou um instrumento para percepção interna do local da ação; ou ainda, como interfaces para interação e ferramenta para mobilização. Todos, invariavelmente, ligados às diversas dimensões do espaço.

\section{Richard Long}

Certa ocasião, tentando entender a expansão sem precedentes pela qual passou a escultura a partir de meados do século XX, deparei-me com o trabalho realizado em 1967: A line made by walking de Richard Long que me fez pensar, pela primeira vez, na experiência da duração.

Era realmente revolucionário, naquele momento, considerar uma caminhada como escultura - que naquele contexto ainda estava muito ligada à experiência com a massa e o volume herdada da tradição - e, ainda mais, por ser um enunciado que existiria ao longo do tempo como instrução e uma fotografia. Segundo Richard Long,

A natureza sempre foi registrada por artistas, desde pinturas rupestres pré-históricas até fotografias de paisagens do século XX. Eu também queria fazer da natureza o assunto do meu trabalho, mas de novas maneiras. Comecei a trabalhar fora usando materiais naturais como grama e água, e isso evoluiu para a ideia de fazer uma escultura andando. ${ }^{7}$

Em 1967, quando ainda estudava na Escola de Arte de St. Martin, em Londres, desenvolve seu primeiro trabalho feito a pé, como um caminho

\footnotetext{
4 Ibidem, p. 210.

5 Ibidem, p. 292.

6 Ibidem, p. 286.

7 Site do artista, disponível em http://www.richardlong.org/.
} 
que dava a "lugar nenhum". ${ }^{8}$ Um trabalho enigmático que documenta por meio de uma fotografia uma ação sua: a criação de uma linha transitória na natureza, feita baseada no repetido ato de andar para frente e para trás em um campo gramado.

No trabalho de Long, o ato de caminhar a pé é um dispositivo para "explorar as relações entre tempo, distância, geografia e medição", ${ }^{9}$ como valores intrínsecos da escultura. Para o artista,

Andar a pé também me permitiu alargar as fronteiras da escultura, que agora tinha o potencial de ser construído no espaço e no tempo de caminhar longas distâncias. Escultura agora podia ser sobre o lugar, bem como material e forma. Eu considero minha paisagem esculturas que habitam o território rico entre duas posições ideológicas, ou seja, de fazer "monumentos" ou, inversamente, de "deixar apenas pegadas". ${ }^{10}$

Para ele, a escultura deve ser "feita no mundo" e, na qualidade de "passeios", precisa ser registrada e descrita em mapas, fotografias e obras textuais, como meio para "alimentar a imaginação" e "destilar a experiência". Nesses trabalhos o tempo não deixa de ser um dispositivo ligado ao espaço. É uma variável que indica "transitoriedade, permanência, visibilidade ou reconhecimento" ${ }^{11}$ do próprio sítio, que é o local da ação. Portanto, trata-se de um raciocínio absolutamente espacial e escultórico, usado como marcador de tempo, distância ou lugar.

\section{Marcel Duchamp}

O primeiro a introduzir o tempo como uma espécie de dispositivo foi Marcel Duchamp. Certa vez, em entrevista a Pierre Cabanne, comenta que "seu maior motivo de orgulho é ter tido a sorte de nunca ter precisado trabalhar para viver",12 pois em suas palavras "A melhor obra de arte é o emprego do seu tempo." ${ }^{13}$ Nesse sentido, o artista defende que viver é

8 Ibidem.

9 Ibidem.

10 Ibidem.

11 Ibidem

12 Cabanne, 1987, p. 21.

13 Ibidem, p. 113. 
"uma questão de quanto se gasta [tempo], ao invés de quanto se ganha". ${ }^{14}$

Marcel Duchamp está no centro da "vertente conceitual" da arte moderna, aquela que passa pelo dadaísmo, pela arte conceitual, pelo minimalismo e pela pop, e que chega ao que chamamos de arte contemporânea. Essa vertente que foi antes um jogo que articula as próprias referências do establishment institucional, em que o objeto artístico está destituído de valor estético, e o artista não se ocupa da matéria plástica como instância única do fazer artístico, e nem com o espaço plástico como única fonte de vivência dos sentidos. Geralmente nos solicita uma experiência de natureza cognitiva e analítica. O espaço agora é entendido como interiorizado.

Ao longo da vida, Duchamp empreendeu uma guerra contra a realidade retiniana da pintura, predominante em sua época. Para ele, a pintura havia se tornado algo da ordem da retina, da sensação, e não da inteligência. Era o momento de sair: "bête comme un peintre" [estúpido como um pintor], segundo Duchamp; e voltar: "la pittura é cosa mentale" [a pintura é uma coisa mental], conforme da Vinci. Ao usar esse jogo de palavras, Duchamp pretendia ressaltar que o mundo havia mudado radicalmente e que os sentidos da visão não correspondiam aos desafios do seu tempo. Não era possível abordar a complexidade do mundo somente com pintura e escultura. Era preciso colocar todos os sentidos em jogo. Ele não queria destruir o objeto de arte mercantil como agente mediador, antes, ao contrário, queria potencializá-lo. Durante grande parte do século $X X$, foi visto como antiartista, alguém que queria destruir a beleza e a arte, mas, diferentemente, foram algumas de suas ideias que as levaram às multidões. Hoje, entendemos que sua obra carrega um aspecto muito generoso por permitir que todos possam produzir arte. Ao deslocar a ênfase do fazer artístico do espaço plástico para o espaço do pensamento, Duchamp abriu caminho para que pessoas sem habilidade faber pudessem ser artistas, pois fazer arte é antes uma questão de pensamento.

O que opera toda essa mudança é a sua invenção do readymade, cuja maior expressão é Fonte, escultura realizada em 1917. A ideia de Duchamp era escolher um objeto que não atrairia pela sua beleza ou pela sua feiura. Para encontrar um ponto de indiferença no olhar. $\mathrm{O}$ readymade nega a possibilidade de julgamento artístico fundado no objeto, belo ou feio. Sua noção se 
confunde com o próprio ato reflexivo acerca do valor da arte. O urinol de Duchamp mudou a maneira de entender, reconhecer e fazer arte. Também alterou significativamente o papel social do artista. Agora, o artista é um jogador num sistema de arte (não podemos esquecer que Duchamp foi um grande enxadrista). Ao fazer tal gesto conceitual, ele introduziu o tempo como circuito, a partir de então algo essencial no ciclo de sua existência.

Segundo Thierry De Duve, ${ }^{15}$ Duchamp, com seu readymade, instituiu o juízo estético moderno ao colocar a pergunta: isto é arte?, em vez de isto é belo (juízo estético kantiano - o belo e o feio respondem a regras normativas). Diante de um porta-garrafas ou de uma roda de bicicleta fixada num banco ou, ainda, de um urinol, não está mais em jogo se isso é "belo", mesmo que se possa achar tudo isso bonito ou feio. Isso já não é mais algo fundamental para a arte. Duchamp desloca o problema formal da arte para a articulação mental e introduz o circuito de arte e sua própria temporalidade, de modo indissociável.

\title{
Cildo Meireles
}

Mas, devo ressaltar um trabalho que acrescenta um outro vetor de sentido para o readymade: o projeto Inserções em circuitos ideológicos, projeto de Cildo Meireles, realizado em 1970. Segundo o artista,

\begin{abstract}
ainda era necessário investigar os aspectos formais da linguagem, [...] para produzir um objeto que pensasse produtivamente (criticamente, avançando e aprofundando) entre outras coisas, um dos mais fundamentais e fascinantes de seus projetos: os readymades de Marcel Duchamp. ${ }^{16}$
\end{abstract}

Em Inserções em circuitos ideológicos 1970-75 — uma compilação de três pequenos textos - Cildo afirma que

não estávamos mais trabalhando com metáforas (representações) de situações, mas com a situação mesmo, real. [...] Era um trabalho que, na realidade, não tinha mais aquele culto do objeto, puramente: as coisas existiam em função do que podiam provocar no corpo social. ${ }^{17}$

15 Arte \& Ensaio, ano V no. 5, 1997, p. 125-149.

16 Meireles, 1999, p. 108.

17 Ibidem, p. 110. 
Estamos falando de um enfrentamento poderoso: a crise da representação. ${ }^{18}$ Como afirmei em outro artigo:

No lugar da operação duchampiana, que foi deslocar um objeto industrial para o circuito da arte e nomeá-lo como tal, Cildo Meireles vai fazer o exercício oposto, pegar um objeto eminentemente simbólico para atuar no meio circulante da economia. [...] Mesmo sabendo que, na prática, o trabalho se dá apenas no plano simbólico, e se cumpre apenas ao enunciar-se poeticamente.

O mais curioso é que Cildo Meireles consegue cumprir sua aventura. Ele, de fato, consegue expandir o readymade e nos deixa um trabalho que é, antes de tudo, um gesto poderoso que aponta um vetor de direção e sentido que se perdeu ao longo da história e que agora, no século XXI, interessa-nos resgatar para atuar diretamente no corpo social, num cruzamento que se dá na membrana da arte, ou melhor, no que denominamos por "economia política da arte".

Cildo propõe a substituição do problema centrado na visualidade plástica por uma prática política. Isso nos interessa porque esta pode ser uma importante ferramenta para enfrentar a temporalidade na era da informação, e mudar o eixo de importância, até agora centrado na visualidade, para a visibilidade, que atue no corpo social, transformando realmente o ambiente da vida humana. Retomando, de certa forma, uma vocação utópica necessária aos dias de hoje. ${ }^{19}$

Cildo introduz o tempo da ação. No vídeo Cildo Meireles, de 1979, dirigido por Wilson Coutinho, ele afirma que seu trabalho tem a ver com a "prática de sonhos e de planos de sabotagem para transformação social", e termina: "Isto é visível." E nós completamos: "Isto é viável".

\section{Lygia Clark}

Voltemos agora ao ano de 1975 para enfrentar um problema levantado por Lygia Clark, e ainda não superado: a "supressão do objeto" ${ }^{20}$ que se anuncia dez anos antes, em 1965, com Caminhando, que pode nos ajudar entender alguns vetores de sentido fundamentais para nossa argumentação.

18 Instaurada, mais ou menos, em meados do século XIX, com o quadro Almoço na relva, de Edouard Manet, apresentado, em 1863, no Salão dos Recusados, inicia um repertório caro à arte moderna e contemporânea, que nos permite navegar até hoje na forma de ideias ou ideais icônicos.

19 Manata, 2014, p. 109.

20 Importante texto publicado na revista Navilouca, em 1975, no qual a artista apresenta o porquê do objeto ser suprimido como questão, tornando-se apenas veículo. 
A partir de 1964, Lygia Clark deixa de lado a matéria dura (a madeira), passa pelo metal flexível dos Bichos e chega à borracha em Obra mole. Essa fita distorcida na Obra mole agora é recortada em Caminhando. Segundo Lygia,

a partir daí, atribuo uma importância absoluta ao ato imanente realizado pelo participante. $\mathrm{O}$ Caminhando tem todas as possibilidades ligadas à ação em si: ele permite a escolha, o imprevisível, a transformação de uma virtualidade em um empreendimento concreto. ${ }^{21}$

É a transferência de poder, do artista propositor para o, agora, participador. Sua preocupação volta-se para uma participação mais ativa do público. Caminhando (1964) é a obra que marca essa transição. O participante é convidado a criar uma fita de Moebius: ${ }^{22}$ a artista propõe que o participador corte uma faixa de papel para, em seguida, torcer uma das extremidades e unir as duas pontas. Depois convida a recortar no comprimento de maneira contínua e, à medida que o faz, ela se desdobra em entrelaçamentos cada vez mais estreitos e complexos. Segundo Lygia, Caminhando diz respeito à escolha,

quando você tiver dado a volta na fita de Moebius, escolha entre cortar à direita e cortar à esquerda do corte já feito. Essa noção de escolha é decisiva e nela reside o único sentido dessa experiência. A obra é o seu ato. À medida em que se corta a fita, ela se afina e se desdobra em entrelaçamentos. No fim, o caminho é tão estreito que não pode mais ser aberto. É o fim do atalho. ${ }^{23}$

O participador agora experimenta um espaço sem avesso ou direito, frente ou verso, apenas pelo prazer de percorrê-lo e, dessa forma, ele mesmo realiza a obra de arte (mas o que importa é a duração e não mais o espaço). A obra se dá na imanência do ato. Para Lygia, o ato de se fazer é tempo, e pergunta "se o absoluto não é a soma de todos os atos, seria esse espaço-tempo onde o tempo, caminhando, se faz e refaz continuamente?"24 Era uma situação-limite e o início de num novo paradigma nas artes visuais brasileiras. $\mathrm{O}$ objeto não estava mais fora do corpo, mas era

21 Clark, 1999, p. 151.

22 Fita ou faixa de Moebius é um espaço topológico conseguido ao se colar as duas extremidades de uma fita, após dar meia volta em uma delas. Deve o seu nome a August Ferdinand Moebius (1790-1868), que a estudou em 1858.

23 Clark, 1999, p. 151.

24 Ibidem. 
o próprio "corpo" que interessava a Lygia. "Existe apenas um tipo de duração: $\mathrm{O}$ ato. $\mathrm{O}$ ato é que produz o Caminhando. Nada existe antes e nada depois." 25 Trata-se da liberação da potência criadora, que só é possível ao se habitar o paradoxo existente entre os regimes macro e microssensorial, condição que poderia ser proporcionada, segundo a artista, pela atuação dos Objetos relacionais. Aí se encontra a importância do dispositivo "prova do real", cuja materialidade e segurança oferecida se tornava fundamental para a manutenção do sujeito entre os dois regimes.

Em "O homem é o centro", publicado no Correio da Manhã, em maio de 1968, numa entrevista dada a Vera Pedrosa, Lygia vai afirmar que

no fundo o objeto não é mais importante", [...] "o pensamento - o sentido que se dá ao objeto, ao ato, é o que interessa: o que vai de nós para o objeto." [...] "Hoje nada tem mais significado pra mim do que a própria realidade das coisas." E conclui afirmando que: "Antes, a expressão era transcendente. O plano, a forma, apontavam para uma realidade que the era exterior. Hoje, na arte, as coisas valem pelo que são em si mesmas. A expressão é imanente. ${ }^{26}$

Em carta enviada a Hélio Oiticica em novembro do mesmo ano, comentando acerca da supressão do objeto, ela vai escrever que

Cada vez mais a frase de [Mário] Pedrosa funciona para o meu trabalho: "O homem objeto de si mesmo". Você vê, a participação é cada vez maior. Não existe mais o objeto para expressar qualquer conceito, mas sim para o espectador atingir cada vez mais profundamente seu próprio eu. ${ }^{27}$

A partir de então, a artista prefere a poética do corpo apresentando proposições sensoriais e enfatizando a efemeridade do ato como única realidade existencial. Em Nostalgia do corpo, Lygia Clark cria objetos que funcionam como entidades vivas, como partes de um corpo que manipulamos e reconhecemos. Suas propostas se caracterizam pelo convite a experiências individuais. Em Estruturação do self, sua última - e mais radical - fase, o trabalho se torna uma obra-acontecimento, realizada na duração e sujeita a imprevisibilidades: os encontros entre a artista e seu público tornam-se sessões terapêuticas que faziam parte de um "tratamento", em que vários

25 Ibidem.

26 Clark, 1999, p. 227-8.

27 Ibidem, p. 236. 
dispositivos sensoriais eram usados, num claro desejo de entrega objetiva; que, nesse caso, é individual e intransferível.

O que Lygia propõe é um paradigma, algo pouco explorado em sua obra, uma nova maneira de olhar o que é o objeto da arte, pois o que presenciamos é o deslocamento da experiência estética objetual centrada nas questões do espaço e da forma para a experiência do tempo (no caso da Lygia, psicológico); que, como consequência, altera por completo o papel social do artista, que tem, agora, uma entrega real, construída por um desejo mútuo, visto que parte da escolha. Não importa mais a experiência do espaço, o que conta agora é a experiência do tempo, da duração, aquela que estabelece a troca, permite a construção da alteridade e, portanto, a entrega. Lygia, com Caminhando, liberta a experiência da arte centrada no espaço e a coloca no tempo.

\section{Guilherme Vaz}

Um dos poucos artistas oriundos das vanguardas modernas (para não dizer o único) que situou seu trabalho inteiramente na experiência do tempo foi Guilherme Vaz. O fez, não para marcá-lo como passagem como em On Kawara, nas séries Today ou One million years; ou dar fisicalidade e espacialização como Marcel Duchamp com sua Sculpture musicale; ou, ainda, formalizar o silêncio como John Cage em 4'33', que são maneiras de dar dimensão espacial ao tempo com base em um método. Guilherme gostava de afirmar que "o que faço é música", não para desconsiderar as questões estéticas dos que investigaram o espaço fundamentados no tempo - pois exercitou vários dos experimentos formais propostos pela vanguarda, criando novos, inclusive, como por exemplo, seu "teatro sonoro" 28 -, mas,

28 No vídeo Uma fração do infinito, de 2013, Guilherme Vaz refaz parte do caminho percorrido pelo cientista inglês Charles Darwin na cidade de Niterói, onde cria uma situação de teatro sonoro em que estabelece, por meio de seus maracás, um diálogo com a floresta e reflete sobre as possibilidades de aprendizado que o universo indígena pode trazer ao mundo ocidental. Segundo Guilherme, em texto publicado na revista Mesa, no. 2, em 2015: Suas referências estão no mundo indígena do Brasil, na floresta, nas formas universais da geometria à mão livre, nas pessoas mais que nos objetos. São sete pontos no infinito com uma poesia simples, mas densa como o silêncio, e livre como o vento. Por isso, é essencialmente arte contemporânea - não possui clímax, todos os seus pontos são iguais em significado. Estes trechos são os primeiros filmados de uma série que pode ir ao infinito, como um cordão de significados livres. 
antes, para marcar sua incomensurabilidade, se não for experimentado pelo corpo unicamente na duração e na dádiva do encontro.

Costumava dizer que,

O meu trabalho, mesmo sendo para os olhos, para o tato e para a mente, é música. Porque meu conceito de música não é música restrita aos ouvidos. Música pode ser para os olhos, o corpo, a língua, pode ser para qualquer coisa. Música para mim é uma atitude diante do mundo. ${ }^{29}$

Guilherme viveu entre "dois mundos", ${ }^{30}$ menos por acaso e mais por necessidade expressiva, numa época regida pelos estritos campos da especialização. Músico de formação ampla, transitou entre o jazz bop, a música sinfônica e a concreta, música popular brasileira e música para cinema, mas foi nas artes visuais e plásticas - mesmo que não tenha adotado como objeto ou questão nem a plástica e nem a visualidade - onde deixou sua maior contribuição ao situar o problema da arte na experiência do tempo.

Detestava a "iconoclastia de boutique" que norteava grande parte dos modernistas, e gostava de afirmar de forma irônica que: "se você seguir o espírito moderno você foge correndo feito uma galinha molhada. Se você seguir o espírito moderno você não dorme dois dias numa fazenda no interior do Brasil". ${ }^{31}$ Sempre pensou e agiu como vanguarda, no sentido do pioneirismo, consciência e combatividade. Rompeu com todos e consigo mesmo, não fazia concessões, fato que o deixou praticamente invisível no plano da cultura. Sua obra é um desenvolvimento contínuo de questões éticas e estéticas na busca de novos campos de ação, tendo a música expandida e sua dimensão corporal o principal eixo.

J. P-Caron afirma que,

Vaz nega que tenha sido em algum ponto um artista visual: sua concepção de mú-

29 Manata, 2016, p. 80.

30 Tradicionalmente, música e poesia eram artes do tempo, pois passam por nossos ouvidos e residem apenas nos corações e mentes; e a pintura e escultura, artes do espaço, por ter aí sua condição de existência. Essa separação perdura até o início do século XX quando as vanguardas modernas começam a se interessar pelas atividades do som. Hoje, não faz sentido pensar em separação, quando ainda existe, é muito mais no campo do discurso que das práticas.

31 Manata, 2016, p. 13. 
sica é que permitiu um transbordamento para além do veículo tido como próprio, o tempo. É, segundo ele, o princípio da instalação em arte: a constituição de um som-espaço. A extensão temporal das obras [musicais] de Vaz o confirma: elas exibem algo da espacialidade. ${ }^{32}$

Uma leitura apressada dessa afirmação - que não deixa de conter sua verdade musical - pode nos fazer pensar que Guilherme tivesse saído da experiência do tempo (música) e ido para a experiência do espaço (arte), algo que não aconteceu; ele nunca saiu da experiência do tempo, o que fez foi incorporar ao tempo a existência do espaço, tornando o tempo o dispositivo central em sua obra.

Nunca deu importância para as "questões do espaço ou da forma", comumente adotadas por seus pares. Não acreditava na produção do "objeto artístico" como mediador mercantil de nossas relações sensíveis no mundo, ao contrário, como diz Frederico Morais, seus trabalhos eram apenas "veículos". ${ }^{33}$ Na maioria das vezes seu trabalho era desprovido de "valor de

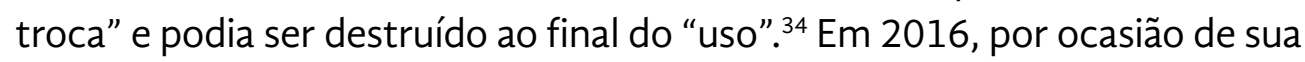
retrospectiva descobrimos que, ainda sim, Guilherme produziu desenhos, pinturas, objetos, esculturas, instalações, performances, trabalhos sonoros, fotografias, filmes e vídeos, não como um problema per si, mas como uma derivação de seus deslocamentos, como fruto de uma existência estética que se dá num tempo estendido. Fez apenas uma exposição em galeria comercial, na Petite Galerie, no Rio de Janeiro, em 1970, fechada na noite de abertura, ${ }^{35}$ e só realizou nova exposição - de carácter institucional - mais

32 Ibidem, p. 111.

$33 \mathrm{Na}$ Cronologia das artes plásticas no Rio de Janeiro - 1816-1994 (p. 306), comentando a participação de Guilherme Vaz no Salão da Bússola, importante marco da arte conceitual brasileira, ocorrido no Museu de Arte Moderna do Rio de Janeiro, em novembro 1969, Frederico Morais vai afirmar: Um outro artista, músico experimental, no mesmo salão, simplesmente comunicava aos visitantes (com o tácito apoio do júri, que considerou válida sua proposta) as experiências a serem feitas - fora do salão. Por exemplo, correr, em qualquer lugar, em espaço aberto ou fechado, verticalmente, em escadas, ou horizontalmente, nas praias, por quanto tempo desejar; ou permanecer em silêncio, em um grupo. A experiência termina com o cansaço do corredor ou com o primeiro barulho. $O$ resultado não é a elaboração de uma determinada obra, mas um enriquecimento do indivíduo. Guilherme Vaz usou o salão (onde marcou com giz, no chão, uma área, colocando-se ali, ao lado de pequenos "sinais") como veículo.

34 Podemos citar como exemplo o objeto/instrumento construído especialmente para o filme de Júlio Bressane: Garoto, em 2015, que foi performado por Vaz e destruído após as filmagens.

35 Um marco importante foi a mostra sequencial "Agnus Dei”, realizada por Cildo Mei- 
de cinquenta anos depois. ${ }^{36} \mathrm{E}$, diferentemente do conceito de obra proposto pelas vanguardas como sendo um arco de conhecimento construído pelo conjunto de trabalhos realizados (geralmente, objetos e espaços), podemos dizer que Guilherme conduziu uma prática artística que não centrava na produção de coisas, mas nas relações que se dão na duração.

\section{Como já havia dito em outro ensaio:}

Para Guilherme, o som é determinante na constituição de uma ontologia do indivíduo; mas não isolado em si mesmo, e sim mundano e, ao mesmo tempo, portador de historicidade; mas também, aberto à transcendência: um estado uníssono com a terra e o mundo que Bornheim denomina de Stimmung, "uma concordância, (co) respondência, através da qual somos a música". ${ }^{37}$ Um estado uníssono dado pela vitalidade rítmica. O som é, antes de tudo, o elemento unificador, que recolhe em si uma densidade que o transcende; pela corporeidade do som. ${ }^{38}$

Em sua obra tudo se encaixa num sistema maior, que extrapola o campo da música ou das artes visuais. Guilherme considera pedras, folhas, formigas, lugares, entes (originários ou não), pensamentos e tudo mais, como

reles, Guilherme Vaz e Thereza Simões, na Petite Galerie, em 1970. Trata-se da primeira mostra de arte conceitual em uma galeria comercial. Cada artista ocuparia uma semana, e o curador, Frederico Morais, a última com um metatrabalho de arte. Guilherme Vaz é o artista que fecha a série, e na mostra afixa à entrada da galeria um aviso que "desapropria" todos os visitantes, com o seu "Projeto de exposição para assassinatos coletivos em alta escala". Manata, esclarece que A exposição de Guilherme durou apenas algumas horas, tendo sido fechada, o motivo, para Frederico Morais, foi a "ameaça de invasão da galeria pela polícia" - talvez por algum tipo de confusão gerada pelo título da proposta que para Guilherme, como relata em depoimento ao Arte Sonora, não passou de um mal-entendido dada à quase total imaterialidade da mostra, pois apresentava um bilhete colado na parede, que estava escrito: "Cada um aqui é uma obra de arte" e, ao fundo da galeria, uma folha A4 datilografada apresentava o seu Ato de desapropriação de datas (área/tempo), que "comunicava" que algumas datas (área/tempo) estavam, a partir daquele momento, "desapropriadas e são obras, contidas pelos seus limites quantitativos, determinados segundo a escala em vigor." (Manata, 2016, p. 163). Nesse gesto, Guilherme informa que "está tudo dentro de você" e, assim, ao "desapropriar" todos os espectadores os transforma em participadores e os transporta para experimentar outras noções de espaço e tempo." (Manata, 2016, p. 36).

36 Em 2016, com curadoria de Franz Manata e organização de Saulo Laudares para a EXST, é realizado no Centro Cultural do Banco do Brasil, no Rio de Janeiro, a primeira exposição institucional de caráter retrospectivo do artista, que no ano seguinte, é apresentada no Sesc Pompeia, em São Paulo. Para baixar o PDF do livro acesse: https://www. academia.edu/42080073/GUILHERME VAZ

37 Bornheim, 1967, p. 5.

38 Manata, 2016, p. 48. 
um todo incrivelmente complexo e, em última instância, tudo que existe é parte de uma única coisa: substância; o mesmo que o filósofo holandês, Espinosa, chama de Deus. ${ }^{39}$

Não quero aqui reivindicar algum aspecto teleológico para seu trabalho, ao contrário, procuro apenas ressaltar o aspecto filosófico de sua obra e a consonância entre "Substância" e "Deus" proposta por Espinosa, que considerava que "todos os objetos - sejam animais, vegetais ou minerais têm mentalidade. Seus corpos e mentes são parte de Deus, que é maior que todos os atributos físicos e mentais do mundo. Deus, para Espinosa, é a "substância" que subjaz à realidade. ${ }^{40}$ Não é algo "transitivo" do mundo algo externo que traz o mundo. Em vez disso, é a causa "imanente" do mundo. Tais questões aparecem em todo o seu percurso, e manifestam-se especificamente no período que esteve no oeste do Brasil, e que somente foram formalizadas por ele em texto escrito para o cineasta Sérgio Bernardes, e publicado em sua fortuna crítica: "O deslitígio do universo", em que afirma:

\begin{abstract}
Estamos dizendo e afirmando que existem sinais de escrita entre os animais e que os seres denominados "árvores" detêm um tipo de conhecimento desconhecido para o homem. Estamos dizendo em todos os sentidos que todos os seres vivos possuem linguagem e mesmo os minerais a possuem. $O$ que isso significa para a arte? Por que é importante essa posição para a arte praticada pelo homem atual e anterior? Em primeiro lugar, e mais importante, ela combate o antropocentrismo letal presente na cultura e na arte ocidental, onde cegos conduzem cegos por ruas de tráfego. Existem sinais claros de arte em todos os seres vivos, inclusive nos translúcidos. Em segundo, e não menos importante, ela irmana o homem com todo o universo engrandecendo-o pela humilhação de sua arrogância homogênica. Estamos propondo o deslitígio do universo. Estamos propondo a convivência de todas as civilizações do universo, conhecidas ou não. ${ }^{41}$
\end{abstract}

Guilherme precisava dar uma outra dimensão ao som, à própria vida e, portanto, ao seu trabalho. Foi seu espírito de invento que o levou a procurar respostas para o "Brasil profundo", para o seu objeto ou leitmotiv, entre

39 Segundo as pesquisadoras Maria Lúcia de Arruda Aranha e Maria Helena Pires Martins, Espinosa parte de uma concepção segundo a qual Deus não é um ser transcendente como tradicionalmente descrito, mas uma Substância que constitui o Universo inteiro e não se separa daquilo que produziu, ou seja, é causa imanente de seus modos, entre os quais está o ser humano. (Aranha e Pires Martins, 2003, p. 328).

40 Aranha e Pires Martins, 2003, p. 129.

41 Vaz, 2016, p. 264. 
outros, e, para tal, não evitou esforços para unir o arcaico com o erudito e dar um enfoque social para o trabalho.

Aos 28 anos, Vaz já havia participado de importantes mostras, como Salão da Bússola, realizado no Museu de Arte Moderna do Rio de Janeiro em 1969; "Information", no MoMA NY, em 1970; e a Bienal de Paris, em 1974, todas, momentos decisivos para a arte conceitual. Depois de uma temporada muito produtiva no Rio de Janeiro, onde participa da nascente cena conceitual em torno das atividades do Museu de Arte Moderna e de se aproximar dos jovens cineastas Nelson Pereira dos Santos e Júlio Bressane, produzindo triIhas para seus filmes - que lhe conferiu o título de precursor da música concreta no cinema brasileiro - , decide sair da cidade. Para Guilherme,

a arte conceitual tem um aspecto de macumba para turista, é uma coisa limpinha com uma palavra em cima. A nossa intenção era outra, estava mais para instalações humanas. Não era uma obra que queria demonstrar um pensamento, ela queria demonstrar uma existencialidade. ${ }^{42}$

Estamos falando de um momento de intensas trocas, aprendizado e produção de trabalhos, mas Guilherme sempre preferiu andar na margem, e como gostava de dizer: era um homem do Oeste, um desbravador. O "mundo" da música não abrigava seu "corpo como um tambor"43 e a cena conceitual lhe parecia muito formal e esquemática. Em busca do que chamo de experiência de "intensidade e duração", abandona a cidade e segue para o Sertão, onde viverá os próximos 20 anos com sertanistas e indígenas do Centro-Oeste e do Norte brasileiro.

Durante esse percurso, articulando prática artística com aspetos políticos e sociais, presidiu a Fundação Cultural de Ji-Paraná, ${ }^{44}$ em Rondônia, na

42 Neves e Manata, 2016, p. 67.

43 Ruiz, 2013, p. 76.

44 Em 1997, Guilherme Vaz vai fundar e dirigir a Fundação Cultural de Ji-Paraná, que Ihe permitiu articular sua prática artística com aspectos políticos e sociais. Em ofício enviado ao Ministério das Comunicações, redigido em março daquele ano, assinado por ele e pelo prefeito Ildemar Kussler, Guilherme dá alguns detalhes de como entendia conceitualmente a ação do Polo Noroeste de Cultura. Seria um local onde "todos os técnicos e empreendedores do Brasil, da Bolívia e do Peru poderão trocar ideias sobre as extraordinárias questões da rota para o Oeste". Guilherme entende que o município de Ji-Paraná, na fronteira ocidental que aponta para o Pacífico, "seria ideal para a criação de um Polo Científico e Intelectual. (Manata, 2016, p. 226). 
fronteira com a Bolívia, onde desenvolveu trabalhos de antropologia, artes visuais e música pré-histórica com os povos indígenas sul-americanos zoró-panganjej, gavião-ikolen e araras.

No Oeste, encontrei um indígena chamado Carlos Bedurap Zoró e pedi a ele que pintasse em maior escala as pequenas pinturas que fazia nos objetos com a ponta de sua lança. Ele começou a praticar pintura indígena e isso foi muito importante para mim. Apesar do meu trabalho passar longe do construtivismo, eu queria que a geometria indígena, feita à mão livre, atingisse uma determinada categoria. Nessa geometria existe uma filosofia, um pensamento de mundo. É uma geometria da vida. Uma das questões que me incomoda no construtivismo brasileiro é que tudo acontece distante da geometria indígena, distante dos sertões. Os desenhos sobre couro dos sertões, por exemplo, são totalmente brasileiros, não tem influência de lugar nenhum. Para que trazer construtivismo russo? Isso é uma besteira. Existem etnias indígenas no Xingu que tem geometrias sensacionais. Eu não componho em sintonia com o construtivismo brasileiro, que reduz o mundo a três ou quatro fórmulas. Você pode ordenar o mundo com uma geometria muito mais avançada, que assuma curvas. A curva é geométrica e você já viu coisa mais brasileira do que a curva? É uma geometria estranha porque o cálculo dela tem um $\mathrm{Pi}$, aquele número infinito. Além disso, ela não fecha e o Brasil é esférico e circular. [...] Ela se organiza em um tipo diferente de ordem, sem exclusão. A curva é social e includente. ${ }^{45}$

O importante nesse gesto é a troca pessoal entre os envolvidos e a possibilidade de que ambos têm de praticar pintura. Não há centralidade do autor. Não há hierarquia, porque não há uma relação entre alta e baixa cultura, de professor e aluno, muito menos de artista que ensina o ofício; o que há é o engrandecimento que se dá pela alteridade. O "resultado" (a tela pintada) não é o problema, e não se revela como pergunta. Essas pinturas - que estão no campo da apresentação e não representação investigam a geometria indígena como "uma filosofia, um pensamento de mundo. Uma geometria da vida". ${ }^{46} \mathrm{O}$ problema nunca consistiu na natureza desse ou daquele objeto, mas nas relações transversais em que os efeitos produzidos por tal ou qual atuam no indivíduo, que sempre podem ser produzidos através de vários meios.

Deleuze, em Conversações, pode nos ajudar a compreender melhor a questão da existência como obra de arte (atributo ético) que envolve a prática artística de Guilherme:

O problema não é ser isto ou aquilo no homem, mas antes o de um devir inumano, 
de um devir universal animal: não tomar-se por um animal, mas desfazer a organização humana do corpo, atravessar tal ou qual sono de intensidade do corpo, cada um descobrindo suas próprias zonas, e os grupos, as populações, as espécies que o habitam. ${ }^{47}[\ldots]$ Posso, assim, dizer que seus métodos tratam-se de "regras facultativas que produzem a existência como obra de arte, regras ao mesmo tempo éticas e estéticas que constituem modos de existência". ${ }^{48}$ "A constituição dos modos de existência ou dos estilos de vida não é somente estética, é o que Foucault chamou de éti$\mathrm{ca}$, por oposição à moral. A diferença é esta: a moral se apresenta como um conjunto de regras coercitivas de um tipo especial, que consiste em julgar ações e intenções referindo-as a valores transcendentes (é certo, é errado...); a ética é um conjunto de regras facultativas que avaliam o que fazemos, o que dissemos, em função do modo de existência que isso implica. ${ }^{49}$

Não estamos falando, nesse caso, de levar a estética à vida, estratégia comumente adotada pelas últimas vanguardas e ainda hoje presente na "estética relacional". O que há é uma estética de vida, um "modo de existência", o que Foucault chama de "estilo de vida", a vida como obra de arte. Mas também como uma ética. Uma relação com o mundo fundada no que Hans Ulrich Gumbrecht chama de "produção de presença", que "aponta para todos os tipos de eventos e processos nos quais se inicia ou se intensifica o impacto dos objetos 'presentes' sobre corpos humanos." 50 Trata-se de uma alternativa não metafísica à cultura hermenêutica predominante nas ciências humanas que procura atribuir sentido aos fenômenos. Ao contrário, Guilherme nos propõe uma experiência de modo não interpretativo, que altera a lógica de que o "outro" é sempre "representado" ou "inventado" segundo os interesses do Ocidente. Eduardo Viveiros de Castro, em Metafísicas canibais, lembra-nos que.

À força de ver sempre o Mesmo no Outro - de dizer que sob a máscara do outro somos "nós" que estamos olhando para nós mesmos - , acabamos por tomar o atalho que nos leva ao que realmente, no fim e no fundo, nos interessa, a saber: nós mesmos. ${ }^{51}$

Essa percepção de mundo fez com que Guilherme, de certa forma, travasse um embate com o construtivismo brasileiro, que, como vimos, afirma

47 Deleuze, 2000, p. 21.

48 Ibidem, p. 123.

49 Ibidem, p. 125.

50 Gumbrecht, 2010, p. 13.

51 Viveiros de Castro, 2018, p. 21. 
ter sido importado. Fato que o leva a fazer proposta para que se "reconsiderasse a geometria indígena e do sertanista" e que, no lugar da geometria euclidiana, se pensasse numa "geometria esférica". Ao afirmar que "a curva é social e includente", ele descola a questão para o campo das relações sociais, o que lhe permite abandonar as questões da representação em favor da apresentação; mudar do "eixo" estético para o ético; e assim alterar a noção de autoria.

Como disse, o que Guilherme fez foi criar uma ontologia do indivíduo, 52 que trata a natureza, a realidade e os seres vivos como algo comum, e que é inerente a todos e a cada um, elaborando um tipo particular de metafísica que, no plano antropológico e/ou filosófico, aproxima-se do "perspectivismo multinaturalista" do pensamento ameríndio, como proposto por Viveiros de Castro, que

\begin{abstract}
trata-se da concepção, comum a muitos povos do continente, segundo a qual o mundo é habitado por diferentes espécies de sujeitos ou pessoas, humanas e não humanas, que o apreendem segundo pontos de vista distintos. ${ }^{53}$ [...] A etnografia da América indígena contém um tesouro de referências a uma teoria cosmopolítica que imagina um universo povoado por diferentes tipos de agências ou agentes subjetivos, humanos como não humanos - os deuses, os animais, os mortos, as plantas, os fenômenos meteorológicos, muitas vezes também os objetos e os artefatos -, todos providos de um mesmo conjunto básico de disposições perceptivas, apetitivas e cognitivas, ou, em poucas palavras, de uma "alma" semelhante. Essa semelhança inclui um mesmo modo, que poderíamos chamar de performativo de apercepção: os animais e outros não humanos dotados de alma "se veem como" pessoas, e portanto, em condições ou contextos determinados, "são" pessoas, isto é, são entidades complexas, com uma estrutura ontológica de dupla face (uma visível e outra invisível), existindo sob os modos pronominais do reflexivo e do recíproco e os modos relacionais do intencional e do coletivo. ${ }^{54}$
\end{abstract}

Além de ter ampliado a linguagem da música e de ter um papel decisivo para a formação da arte conceitual brasileira no contexto das vanguardas, sua obra nos permite fazer uma "ponte" direta entre a vanguarda moderna e a "arte atual", 55 produzida neste século, sob a égide da economia do

52 Trata-se de uma reflexão a respeito do sentido abrangente do ser, como aquilo que torna possível as múltiplas existências, como no sentido heideggeriano.

53 Viveiros de Castro, 2004, p. 225.

54 Viveiros de Castro, 2018, p. 43 e 44.

55 "Arte atual" é uma apropriação de um termo usado por Frederico Morais para designar uma arte que ainda não havia sido nominada e que veio a se chamar "arte conceitual". 
conhecimento. Que ainda não foi nomeada e que está centrada na experiência de um tempo expandido; que não se dá no tempo do instante, mas sim na duração; que não tem o objeto mercantil plástico ou visual como questão; e que tem no tempo seu maior dispositivo.

Guilherme tinha clareza do seu papel e de que havia criado "novos mundos" a seu tempo e modo. Olhar para sua obra agora, de forma retrospectiva, instigado por questões operadas em nossa prática artística, ${ }^{56}$ permite identificar que Guilherme nos aponta mais um possível léxico para a arte, com conceitos e apreensões particulares, que altera o papel social do artista e o próprio objeto da arte, ao tornar o tempo dispositivo.

\section{Q.E.D.}

Como queria demonstrar, o que nos interessa aqui ressaltar é o trabalho de arte e a natureza do objeto artístico que, normalmente, usamos como instrumento de mediação objetiva no mundo, como condição imanente ao indivíduo e que não exclui a tradição transcendente. Temos produzido um tipo de arte que não é centrada na produção de objetos e coisas, mesmo que apareçam como veículos que, em seguida, possam ser comercializados. No nosso entender a obra é o seu ato, e o objeto não está mais fora do corpo, é o próprio "corpo" (do artista e do outro). Para nós é o tempo da ação, porque o ato de se fazer é tempo. O tempo como dispositivo.

Tal fato nos permitiu abandonar o problema da representação em favor da apresentação, deslocando a experiência estética objetual centrada nas questões do espaço e da forma para a experiência do tempo. E aí, as questões desdobradas em torno da crise da representação, na forma de ideias e ideais icônicos, deixam de ser central, mas se mantêm como um meio possível. O que estamos propondo é uma experiência de modo não interpretativo, mudar do "eixo" estético para o ético e, assim, alterar a noção de autoria ao deslocar as questões para o campo das relações sociais.

56 Trabalho que teve início em meados dos anos noventa e que já naquela época se interessava em entender como seria a arte na era da economia da informação. 
Temos conduzido uma prática artística que se manifesta na condição de programas em processo, cuja apreensão poética se dá num tempo expandido, na experiência da duração dos encontros e suas reverberações. É a existência como obra de arte, que é antes um atributo ético. É uma atitude diante do mundo. Uma filosofia, um pensamento de mundo como substância, que envolve uma entrega pública real e uma mudança do papel social do artista.

O que estou falando se assemelha a uma espécie de "jogo" de longa duração em que o jogador assume várias posições. Ele pode ser audiência, consumidor, espectador, ou participador, mas sempre segundo sua escoIha pessoal. Durante a parada não há distinção hierárquica entre as partes. O que se estabelece é um processo de estar artista. Um estado de conaturalidade, com tudo e todos que estão no tabuleiro e ao redor dele, pois nesse jogo todos jogam, não só os especialistas. Nesse jogo, tem um papel importante o som - qualquer um e especificamente a oralidade - que é determinante na constituição ontológica do jogador (o indivíduo). Por ser fruto da escolha, está aberto à imanência: um estado uníssono com a terra e o mundo dado pela vitalidade rítmica, que é o elemento unificador, que recolhe em si uma densidade que o transcende, pela corporeidade do som.

Esse jogo evoca um tipo de geometria circular, que altera a noção de construção e circuito. Seu tabuleiro não se estrutura em fórmulas conceituais, que produzem objetos e coisas, mas procura transformar uma virtualidade em um empreendimento concreto. Por se tratar de uma geometria da vida organiza-se em um tipo diferente de ordem, sem exclusão. O importante nesse jogo é a troca pessoal entre os envolvidos, o engrandecimento que se dá pela alteridade. O "resultado", além do divertimento, é a produção de presença.

Portanto, achamos que é urgente entender o jogo que está em curso na arte, que engana nossa percepção, cujas regras estão dadas mas que podem ser reescritas e reelaboradas durante a própria partida. Se no início do século vinte o jogo foi transferir a operação poética da transformação matérica para a estruturação mental mediante a introdução da noção de circuito; agora, parece-nos produtivo - como mais uma possibilidade situar a operação conceitual na "membrana" do sistema e articular a existência artística, e sua fricção com os demais campos, no que denominamos por "economia política da arte" - uma interface entre o sistema de arte e os demais campos da cultura, bem como sua dimensão econômica, política e social -, fato que por consequência nos permite enfrentar a temporalidade da era do conhecimento. 
Essa arte atual, esse jogo que ainda não foi nomeado e que está centrado na experiência de um tempo expandido e não se dá no tempo do instante, mas sim na duração, tem no tempo seu maior dispositivo. Tais questões nos apontam mais um possível léxico para a arte que, como disse, possui conceitos e apreensões particulares, que altera o papel social do artista; a maneira de transmitir conhecimento e seu modo de circulação; e o próprio objeto da arte.

Por fim é preciso lembrar que esse é um texto de artista de cunho estético e caráter filosófico, que vem sendo construído em processo e, portanto, sem o recuo necessário, e que não pretende esgotar os problemas aqui colocados.

Tais questões, que surgem a partir de nossa prática artística, aparecem em programas de escrita visual (exposições, happenings e performances) e textual (publicações). E, como parte desse jogo aberto, é um pequeno sistema que ainda está sendo construído e entendido, por estar sendo vivido. Assim, convidamos você, interlocutor, a participar. Ou melhor, obrigado por já estar no jogo.

Franz Manata

Rio de Janeiro, 2020

\section{Referências}

32a. Bienal de SP: Incerteza Viva (catálogo). Organização de Jochen Volz e Júlia Rebouças. São Paulo: Fundação Bienal de São Paulo, 2016.

ARANHA, Maria Lúcia de Arruda; PIRES MARTINS, Maria Helena. Filosofando: introdução à filosofia. São Paulo: Moderna, 2003.

BORNHEIM, Gerd A. Sobre a linguagem musical - II. O Estado de S. Paulo. São Paulo, 16 de setembro de 1967. Suplemento Literário, p. 5.

CABANNE, Pierre. Marcel Duchamp: engenheiro do tempo perdido. São Paulo: Perspectiva, 1987.

CLARK, Lygia. Lygia Clark. Rio de Janeiro: Paço Imperial, 1999.

DELEUZE, Gilles. Conversações. São Paulo: 34, 2000.

DUCHAMP, Marcel. Marcel Duchamp. Milão: Bompiani, 1993. 
ESPINOSA, Baruch. Ética. São Paulo: Autêntica, 2007.

FERREIRA, Glória. org. Arte \& Ensaio, ano V no. 5. Rio de Janeiro: UFRJ, 1998.

GUMBRECHT, Hans Ulrich. Produção de presença: O que o sentido não consegue transmitir. Rio de Janeiro: Contraponto, PUC-Rio, 2010.

MANATA, Franz. Som e imagem no nosso tempo. In: FERREIRA, Glória; ERNESTO, Luiz (Orgs.). A imagem em questão. Rio de Janeiro: EAV Parque Lage, 2014.

. Guilherme Vaz: uma fração do infinito. Rio de Janeiro: EXST, 2016.

MEIRELES, Cildo. Cildo Meireles. Organização de Paulo Herkenhoff, Gerardo Mosquera e Dan Cameron. São Paulo: Cosac Naify, 1999.

MORAIS, Frederico. Cronologia das artes plásticas no Rio de Janeiro (18161994). Rio de Janeiro: Topbooks, 1995.

NEVES, Caio; MANATA, Franz. Guilherme Vaz: eu sou o que posso ser. In: MANATA, Franz (Org.). Guilherme Vaz: uma fração do infinito. Rio de Janeiro: EXST, 2016.

RUIZ, Giselle. Arte/Cultura em trânsito - O MAM/RJ na década de 1970. Rio de Janeiro, Mauad; Faperj, 2013.

Site do artista Richard Long. http://www.richardlong.org/. Acessado em 02/02/2020.

VIVEIROS DE CASTRO, Eduardo. Metafísicas canibais: elementos para uma antropologia pós-estrutural. São Paulo: Ubu, 2018.

. Perspectivismo e multinaturalismo na América indígena. O Que Nos Faz Pensar, Rio de Janeiro: PUC-Rio, nº 18, p. 225-254, 2004.

VAZ, Guilherme. Uma fração do infinito. Revista MESA (Espaços poéticos = linguagens éticas: diversas práticas na América Latina), Instituto Mesa, no. 2, 2015.

. O deslitígio do universo. In: MANATA, Franz (Org.). Guilherme Vaz: uma fração do infinito. Rio de Janeiro: EXST, 2016. 